\title{
Suitability of the health and social care resources for persons requiring long-term care in Spain: An empirical approach
}

\author{
Jorge Garcés ${ }^{\mathrm{a}, *}$, Francisco Ródenas ${ }^{\mathrm{a}, 1}$, Vicente Sanjosé ${ }^{\mathrm{b}, 2}$ \\ a "Poliwelfare" Research Unit, Department of Social Work and Social Services, Universitat de València, Spain \\ b “Poliwelfare” Research Unit, Department of Science Education, Universitat de València, Spain
}

\begin{abstract}
The objective of this paper is to examine the suitability of specific facilities for dependent persons for meeting users' needs. A total of 1265 users of social and health facilities for dependent persons were interviewed in a study carried out in a typical southern European region with a Mediterranean welfare system: the Valencia Autonomous Region in Spain. Data were obtained on users' socio-demographic profile, health, functional dependence, cognition, social support and housing suitability. Based on these data and the institutional definitions of the specific facilities for dependent persons, the suitability index was drawn up for each facility and suitability was evaluated using discriminant analysis. The results give a high suitability index for most of the facilities (between 0.661 for Units for Home Hospitalisation and 1.000 for Units for Psychiatric Hospitalisation). But a significant percentage of patients (17\% in Hospitals for Chronically Ill and Long-stay Patients) could be cared for in different facilities to the ones they actually use.
\end{abstract}

(C) 2005 Elsevier Ireland Ltd. All rights reserved.

Keywords: Suitability; Care; Health

\footnotetext{
* Corresponding author. Present address: Universitat de València, Facultad de Ciencias Sociales, Departamento de Trabajo Social y Servicios Sociales, Avda. de los Naranjos, s/n. 46022 Valencia, Spain. Tel.: +34 96 3828184; fax: +34 963828188 .

E-mail addresses: jordi.garces@uv.es (J. Garcés), francisco.rodenas@uv.es (F. Ródenas),vicente.sanjose@uv.es (V. Sanjosé)

${ }^{1}$ Universitat de València, Facultad de Ciencias Sociales, Departamento de Trabajo Social y Servicios Sociales, Avda. de los Naranjos, s/n. 46022 Valencia, Spain. Tel.: +34 96 3828202; fax: +34 96 3828188.

${ }^{2}$ Universitat de València (Estudi General), Facultad E.U. Magisterio "Ausias March", Departamento de Didáctica de les Ciències Experimentals i Socials, C/Alcalde Reig, 8. 46006 Valencia, Spain. Tel.: +34 96 3864480/83; fax: +34963864487.
}

\section{Introduction}

The development of welfare states in Europe over recent decades has brought an increase in the size of the health care sector for all of them [1], together with very significant problems in management [2] and finance [3], especially in the Mediterranean group of countries. One of the reasons for the increase in expenditure is the rising demand for health services from dependent persons, resulting from the process of ageing (in 2003 there were 74 million people aged 65 or over in the EU-15, as opposed to 38 million in 1960, and the percentage rose from $16 \%$ in 2004 to $27 \%$ in 2010) [4], the increase in the dependent popula- 
tion $(21 \%$ of the European population aged 65 or over presents a high degree of dependence for the activities of daily life (ADL)) [5] and the crisis in informal support (employment for women and changes in values and family structure). These problems threaten the very survival of the protection system [6,7]. The basic reason for all the problems is the growing demand for high quality services [8] aimed at raising quality of life for users.

The purpose of the study was to evaluate the suitability of the social and health facilities to meet the needs of dependent persons cared for in institutional facilities. No previous studies had been carried out in Spain, at least not with the same scope, although some have been carried out in the UK [9]. In Spain, the studies carried out covered inappropriate use of hospitals, based on the appropriateness evaluation protocol (AEP) [10], or the lack of specialist geriatric units in hospitals for acute patients allowing adaptation of such hospitals to the ageing population [11].

Dependent persons are those with reduced autonomy for carrying out the activities of daily life who, thus, need the help of another person. They require the assistance of health and social welfare sectors which are very complex to co-ordinate [12].

In this paper, we show the results obtained from a field study carried out in the Valencian Autonomous Region in Spain, during 2001 [13]. The Valencian Autonomous Region has the typical characteristics of Mediterranean models for social welfare [14], and is similar to most regions in Portugal, Italy and Greece [15]: late provision of social protection systems in comparison with other European countries, a high degree of influence from the Catholic church in the area of social assistance, a high degree of dependence on the family as a source of personal welfare services and a low level of institutional, social expenditure.

The specific social services for dependent persons that are available in Valencia and were covered in the study are institutionally defined as follows [16]:

- Nursing Homes. Centres designed to serve as a stable, communal home for elderly persons having problems of dependency and social problems which prevent them from continuing to live in their own homes. Nursing homes offer support for the activities of daily life, health supervision, rehabilitation programmes and holistic geriatric care.

- Day Centres. Centres for the outpatient treatment of elderly, dependent persons who have social or family support allowing them to remain in their own homes at night and/or during part of the day. They offer catering services, help with personal hygiene, functional and cognitive rehabilitation, medical care, adapted transport and leisure activities.

- Home Help Service. Domestic and personal care in the home for elderly persons aged 60 or over or disabled persons of any age who are dependent for the activities of daily life. The aim is to postpone or avoid admission in residential centres.

- Phone Assistance. Emergency service for elderly persons with health risks who live alone.

The institutional definitions of the specific health services for dependent persons studied here are:

- Hospitals for Chronically Ill and Long-stay Patients. Hospitals for patients requiring long-duration health care, intensive rehabilitation and/or palliative care in terminal conditions.

- Units for Psychiatric Hospitalisation. These units are located in hospitals for acute patients and provide intensive treatment for mental patients under a continuous care regime.

- Units for Mental Health. Outpatients services which care for people with mental health problems who are referred from primary care.

- Units for Addictive Conduct. These provide outpatient health care for persons who have problems arising from the consumption of alcohol, drugs or other addictive substances, compulsive gambling, etc.

- Units for Home Hospitalisation. These provide specialised health care at home after hospital discharge.

This network of facilities is most effective and achieves most care benefits when dependent patients are allocated to the most suitable facility [17].

The care benefits for dependent persons can be increased if the following parameters are optimised:

(a) Suitability of the facilities to the specific needs of each dependent person [18]. It is possible to define the health care profile of each facility and establish which of them, or which combination, should be used in each case in order to maximise the patient's quality of life. 
(b) Increased opportunities to use facilities for the population as a whole through adequate management of services in patients' referral itineraries. This will have important economic implications when patients are referred from hospitals to outpatients and home services [19].

We examined the suitability of health and social care services for the patients covered by the study in two sections:

1. Badly-placed patients, who are allocated to unsuitable facilities.

2. Patients cared for in facilities but who could be cared for in others.

\section{Methods}

The data used in this study were obtained from a field study [13] involving direct interviews with the users of the different social and health facilities described above.

The questionnaire was drawn up and validated specifically for this study to obtain information on: social and demographic data (age, gender, marital status and education); clinical diagnosis and treatment (type of pathologies suffered, illness stage, clinical complexity); living environment; functioning using the Barthel test [20] and the Frenchay test [21]; cognitive state using a Spanish adaptation of the Mini-Mental State Examination by Folstein et al. (1975) [22] carried out by Lobo et al. (1979) [23]; social support (presence or absence of a carer, whether or not the user lives alone, distance between the user and his or her family); and social and demographic data and attendance by the carer.

Sampling points and users were selected by multistage, stratified, random sampling in each stratum (i.e. health and social care). The intended sample size was 1300 users and the actual sample size was 1265: 709 from health services, and 556 from social services. This was large enough to give a $95 \%$ confidence level for assessing fractions within $\pm 4.1 \%$ of an observed overall percentage for the social care stratum and $\pm 3.7 \%$ for the health care stratum $(p=q=0.5)$.

In order to evaluate whether a user is correctly allocated to a specific service or facility, two approaches were used: (a) Evaluation of a criterion based on the comparison of the user profile with the typical user for which the social or health facility was designed (external criterion).

(b) Evaluation based on the norm, that is, the comparison of the user profile studied with the characteristics of the users who actually are cared for by this facility. This procedure informs us about the possibility that some patients might be cared for by other facilities, in that they have profiles which are similar to those of patients cared for at these.

In order to relate the suitability of each facility to its users, we used indicators based on the following independent variables:

- Age: the law in Spain requires that patients be at least 60 years of age in order to enter a Nursing Home. Several specific resources for persons needing longterm care are designed for the elderly, that is persons aged 65 or more, or for the frail aged 75 or more.

- Type of illness: presence or absence of chronic illness and serious pathologies, both mental and physical.

- Stage of the illness: a distinction is made between the terminal stage when palliative care is required and critical episodes in patients with several chronic pathologies requiring stabilisation.

- Clinical complexity: depending on the need for clinical and technical nursing procedures required by the user (Box 1).

- Functional capacity: degree of dependence for ADL, measured by the Barthel and Frenchay tests and the Mini-Mental State Examination.

- Social support: whether or not there is a person who can provide the user with the necessary care. In this study, a suitable carer is considered to be a person aged under 75, either present or mentioned by the dependent person interviewed, who either belongs to the patient's family or has been taken on to care for the user as long as is necessary.

Based on the institutional definition of facilities (see Section 1 above) and the above variables, we established the typical theoretical profiles for each of the facilities analysed (Box 2).

In order to evaluate the suitability of facilities for users, we initially estimated the percent- 


\section{Box 1: Definition of clinical complexity}

\begin{tabular}{|ll|}
\hline The patient needs: & $\begin{array}{l}\text { Clinical } \\
\text { complexity }\end{array}$ \\
$\begin{array}{l}\text { Enteral or parenteral feeding, assisted breathing or respiratory therapy, chest drain or } \\
\text { transfusion, fluid therapy, respiratory or functional physiotherapy, chemotherapy, radiotherapy, } \\
\text { biopsy, complex cures, ostomy or tracheotomy care, dialysis. }\end{array}$ & Yes \\
$\quad$ None of the above, but perhaps oxygen treatment, medication, psychotherapy, blood & No \\
analysis, etc. & \\
\hline Source: "Poliwelfare" Research Unit, Universitat de València, 2004. & \\
\hline
\end{tabular}

\section{Box 2: Typical user profile for each facility}

Centres and services
Social
Nursing Homes
Day Centres
Home Help Service
Phone Assistance
Health
Hospitals for Chronically III
and long-stay Patients

Units for Psychiatric Hospitalisation

Units for Mental Health

\section{User profile}

Residents of nursing homes in Spain must be persons over 60 years old without a suitable carer, dependent on instrumental activities of daily living (IADL), with moderate, severe or total dependence in basic activities of daily living (BADL) or cognitive failure.

Users must be over 60 without clinical complexity, with a suitable carer, dependent for IADL, suffering moderate, severe or total dependence for BADL or cognitive failure.

Users with no clinical complexity, dependent for IADL, who:

-Have a suitable carer.

-Do not have a suitable carer or live alone, but are independent or have slight dependence in BADL and are fully conscious (i.e. without mental confusion or obnubilation nor stupor).

Persons without clinical complexity, dependent for IADL with no suitable carer or living alone, but are fully conscious (i.e. without mental confusion or obnubilation nor stupor), and independent or only slightly dependent in BADL.

Chronic cases:

-Dependent for BADL

-Terminal stage needing palliative care

-Elderly patients aged over 75

-Clinical complexity

-Convalescence following stabilisation after a critical episode

Patients suffering serious, chronic mental pathologies (dementia, schizophrenia, personality disorders and other psychoses) or who are suffering from acute episodes of neurotic disorders.

Persons with mental disorders, without clinical complexity, in any of the following situations:

-Can look after themselves: independent or with a slight or moderate dependence for IADL.

-Patients who cannot look after themselves but have a suitable carer and severe or total dependence for IADL. 


\section{Box 2: (Continued)}

Units for Addictive Conduct

Units for Home Hospitalisation

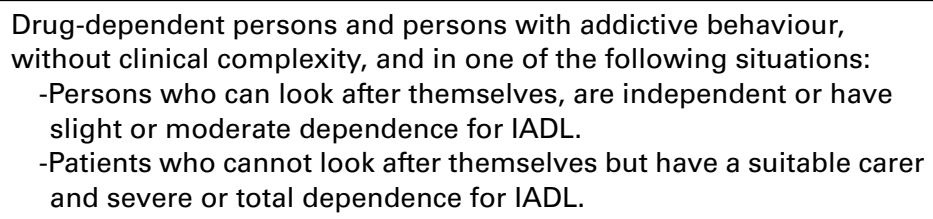

Drug-dependent persons and persons with addictive behaviour, without clinical complexity, and in one of the following situations:

-Persons who can look after themselves, are independent or have slight or moderate dependence for IADL.

-Patients who cannot look after themselves but have a suitable carer and severe or total dependence for IADL.

Patients referred by a hospital for critical care, having a suitable carer in one of the following situations:

-With a chronic illness

-Terminal stage needing palliative care

-Elderly persons aged over 75

Source: “Poliwelfare” Research Unit, Universitat de València, 2004.

age of persons cared for at facilities different from the appropriate ones through discriminant analysis which uses as a dependent classification variable the type of facility used, and as independent variables those variables considered important to evaluate user profiles.

Discriminant analysis compares all the cases considered with each other in accordance with the discriminating variables introduced and evaluates the similarities or differences existing between them. This procedure cannot determine whether the profiles calculated are suitable or not for the facilities: an internal rather than an external evaluation criterion is used to reveal the possibility of some patients being cared for at other facilities, because they have profiles similar to patients cared for at these.

\section{Results}

\subsection{Suitability of resources to user profiles}

Table 1 gives the relevant variables for the ideal user profile for each social facility analysed. The percentages of people who meet each of the criteria in the institutional profile for each social facility are shown separately. Finally, the table gives the percentage of users of each resource who both meet all the requirements and are defined by the suitability index.

There is a high index of users with suitable profiles for each facility who, therefore, have been allocated correctly. The exception are Nursing Homes, in which $32.6 \%$ of users are completely independent for ADL. This situation is common in many parts of Spain.

Table 1

Social services: percentage of users for each variable and suitability index

\begin{tabular}{lcccc}
\hline Criteria & \multicolumn{2}{l}{ Social centres and services } & & \\
\cline { 2 - 5 } & Nursing Homes & Day Centres & Home Help Service & Phone Assistance \\
\hline Aged over 60 (\%) & 100 & 100 & - & - \\
Suitable carer (\%) & 0.4 & 91.4 & 52.9 & 18.6 \\
Living alone (\%) & - & - & 41.2 & 76.7 \\
Moderate, severe or total dependence for BADL (\%) & 32.8 & 62.9 & 51.8 & 86.0 \\
Cognitive failure (\%) & 62.6 & 96.3 & - & - \\
Degree of awareness: alert (\%) & - & - & 82.4 & 95.3 \\
Without clinical complexity (\%) & - & 91.4 & 100 & 100 \\
Users meeting all criteria (\%) & 67.4 & 85.8 & 83.7 \\
Suitability index & 0.674 & 0.914 & 0.858 & 0.837
\end{tabular}

Source: "Poliwelfare" Research Unit, Universitat de València, 2004. Survey of Social and Health Care Needs in the Valencian Autonomous Region, 2001. 
Table 2

Health services: percentage of patients for each variable and suitability index

\begin{tabular}{|c|c|c|c|c|c|}
\hline \multirow[t]{2}{*}{ Criteria } & \multicolumn{5}{|c|}{ Health centres and services } \\
\hline & $\begin{array}{l}\text { Units for Home } \\
\text { Hospitalisation }\end{array}$ & $\begin{array}{l}\text { Hospitals for } \\
\text { Chronically Ill and } \\
\text { Long-stay Patients }\end{array}$ & $\begin{array}{l}\text { Units for } \\
\text { Mental Health }\end{array}$ & $\begin{array}{l}\text { Units for } \\
\text { Addictive Conduct }\end{array}$ & $\begin{array}{l}\text { Units for } \\
\text { Psychiatric } \\
\text { Hospitalisation }\end{array}$ \\
\hline Aged over $75(\%)$ & 51.6 & 49.8 & - & - & - \\
\hline Suitable carer (\%) & 70.6 & - & 50.0 & 53.6 & - \\
\hline $\begin{array}{l}\text { Moderate, severe or } \\
\text { total dependence for } \\
\text { BADL }(\%)\end{array}$ & - & 61.1 & - & - & - \\
\hline $\begin{array}{l}\text { Independent, slight or } \\
\text { moderate depen- } \\
\text { dence for IADL } \\
(\%)\end{array}$ & - & - & 85.5 & 72.5 & - \\
\hline Acute patients $(\%)$ & - & 28.1 & - & - & - \\
\hline Chronic patients (\%) & 84.6 & 100 & - & - & - \\
\hline Mental patients (\%) & - & - & 100 & - & 100 \\
\hline $\begin{array}{l}\text { Patients with addic- } \\
\text { tions }(\%)\end{array}$ & - & - & - & 100 & - \\
\hline Terminally ill (\%) & 18.6 & 8.1 & - & - & - \\
\hline $\begin{array}{l}\text { Clinical complexity } \\
(\%)\end{array}$ & - & 23.8 & 0 & 0 & - \\
\hline $\begin{array}{l}\text { Patients meeting all cri- } \\
\text { teria }(\%)\end{array}$ & 66.1 & 82.2 & 92.0 & 89.9 & 100 \\
\hline Suitability index & 0.661 & 0.822 & 0.920 & 0.899 & 1.000 \\
\hline
\end{tabular}

Source: "Poliwelfare" Research Unit, Universitat de València, 2004. Survey of Social and Health Care Needs in the Valencian Autonomous Region, 2001.

In the case of Day Centres, the few incorrectlyplaced users are people who do not have a suitable carer but who cannot or do not want to go to a Nursing Home. The Home Help Service is used inappropriately for some people who do not have a suitable carer or who live alone and are dependent. Finally, Phone Assistance is used inappropriately in people who have a suitable carer or who do not live alone.

Table 2 shows the percentages of users at each of the health facilities analysed, and those for users who meet all the requirements of the institutional profile for ideal patients.

In most health facilities, the percentage of users with the appropriate profile is very high, except in Units for Home Hospitalisation. In the latter, the criterion which limits suitability is the existence of a suitable carer. When the only requirement is the existence of a carer (part-time or occasional), the percentage of well-placed patients increases to $88.7 \%$. However, there is still a small percentage of patients who have no carer and who should not be using this service. The percentage of wrongly-placed patients in Hospitals for Chronically
Ill and Long-stay Patients is high because a large number of these centres care for a large number, as many as $50 \%$, of people aged under 75 with no clinical complexity and who are not terminally ill. Such patients could be cared for in other non-specific units for dependent persons.

In Units for Mental Health and Units for Addictive Conduct, there is a small percentage of patients who have no carer and have severe or total dependency for instrumental activities of daily living (IADL) and who have, therefore, been wrongly placed.

In Units for Psychiatric Hospitalisation, the suitability criterion is the specific pathology in each case. In this area, all the patients covered by the field study were correctly placed. $63.1 \%$ of patients were schizophrenic, $27.7 \%$ had acute neuroses, and $7.7 \%$ had personality disorders.

\subsection{Suitability of facilities to user profiles}

In particular, we studied the patients cared for at Units for Psychiatric Hospitalisation and those admit- 
Table 3

Classification resulting from discriminant analysis for mental and drug dependence patients

\begin{tabular}{llccc}
\hline Centre or service used & Forecast facility & & \\
\cline { 2 - 5 } & Unit for Mental & Unit for Addictive & Total (\%) \\
& Health $(\%)$ & 3.4 & Hospitalisation $(\%)$ & 5.1 \\
Unit for Mental Health & 91.5 & 79.7 & 4.4 & 100 \\
Unit for Addictive Conduct & 15.9 & 6.3 & 71.8 & 100 \\
Units for Psychiatric Hospitalisation & 21.9 & 100 \\
\hline
\end{tabular}

Source: "Poliwelfare" Research Unit, Universitat de València, 2004. Survey of Social and Health Care Needs in the Valencian Autonomous Region, 2001.

ted to Hospitals for Chronically Ill and Long-stay Patients, as the possible referral of some of these patients to other facilities would mean a greater chance of their use through freeing up beds, as well as greater quality of life for the patients.

The discriminant analysis was carried out using the SPSS application, version 12.0, introducing the following as independent variables: the level of social support, the mental and physiological disorders suffered, the number of types of illness, the clinical procedures used, the current stage of the patient's illness, the Barthel rating, the Frenchay rating, and the Mini-Mental State Examination rating.

So, we use the clinical profile that we have for the patient, their levels of cognitive and functional dependence, and the level of social support in the family environment of the dependent person.

\subsection{The mentally ill}

Patients with mental disorders can be cared for at the following facilities: Units for Psychiatric Hospitalisation and Units for Mental Health (outpatients). To these we can add the Units for Addictive Conduct, which deal above all with drug addicts and alcoholics, but also persons with mental disorders resulting from addiction.

Taking the Unit for Psychiatric Hospitalisation as a reference we asked how many patients cared for at other resources could be cared for at this unit, and how many patients admitted to the Hospital could be cared for at other resources for the mentally ill.

If the theoretical classification is compared with the empirical one, differentiating by facilities (Table 3), the most relevant figure is the high percentage of wellplaced users, a total of $87.6 \%$. The Units for Psychiatric Hospitalisation have the highest proportion of users whose social and health profile is most similar to that of other groups, especially mental health units. The latter are the natural alternative to hospitalisation when mental patients have been stabilised and are no longer suffering acute episodes. Note that $28.2 \%$ of hospitalised mental patients suffer from acute neurotic episodes, and most of them could be referred to out-patient units.

Naturally, the weighting of the different variables used in the discriminant analysis causes variations in the forecast group for each patient, especially for their medical and psychological diagnosis. This is seen when analysing the result for Units for Addictive Conduct in which discriminant analysis shows that almost $20 \%$ of users could be treated in other facilities, especially Units for Mental Health. The specific nature of their addiction-related disorders is the reason why they were referred to the units in which they are currently receiving treatment.

\subsection{Fragile elderly and chronically ill patients}

Elderly patients suffering from chronic, degenerative and/or acute illnesses can be cared for in Nursing Homes (with greater or lesser care), in Hospitals for Chronically Ill and Long-stay care patients, or at home through Units for Home Hospitalisation, or even through Day Centres and the Home Help Service, depending on their levels of functional dependence and clinical state.

Regarding Hospitals for Chronically Ill and Longstay Patients, we asked which patients admitted showed profiles similar to those using other resources and how many users of other resources could be cared for within such hospitals.

Table 4 shows the results of the theoretical classification of patients and comparison with empirical classification. 
Table 4

Classification resulting from discriminant analysis for patients currently using Hospitals for Chronically Ill and Long-stay Patients

\begin{tabular}{|c|c|c|c|c|c|c|c|}
\hline \multirow[t]{2}{*}{ Resource used } & \multicolumn{6}{|c|}{ Forecast facility } & \multirow[t]{2}{*}{ Total (\%) } \\
\hline & $\begin{array}{l}\text { Nursing } \\
\text { Home } \\
(\%)\end{array}$ & $\begin{array}{l}\text { Day } \\
\text { Centre } \\
(\%)\end{array}$ & $\begin{array}{l}\text { Phone } \\
\text { Assistance } \\
(\%)\end{array}$ & $\begin{array}{l}\text { Home Help } \\
\text { Service (\%) }\end{array}$ & $\begin{array}{l}\text { Unit for Home } \\
\text { Hospitali-sation } \\
(\%)\end{array}$ & $\begin{array}{l}\text { Hospital for } \\
\text { Chronically Ill and } \\
\text { Long-stay Patients } \\
(\%)\end{array}$ & \\
\hline Nursing Home & 72.9 & 1.9 & 8.9 & 14.0 & 0.4 & 1.9 & 100 \\
\hline Day Centre & 11.1 & 70.4 & 3.7 & 14.8 & - & - & 100 \\
\hline Phone Assistance & 5.0 & 2.5 & 80.0 & 12.5 & - & - & 100 \\
\hline Home Help Service & 20.3 & 7.2 & 18.8 & 50.8 & 2.9 & - & 100 \\
\hline Unit for Home Hospitalisation & 3.0 & 3.6 & 3.6 & 2.3 & 70.8 & 16.7 & 100 \\
\hline $\begin{array}{l}\text { Hospital for Chronically Ill } \\
\text { and Long-stay Patients }\end{array}$ & 2.2 & 3.0 & 3.0 & 4.4 & 4.4 & 83.0 & 100 \\
\hline
\end{tabular}

Source: "Poliwelfare" Research Unit, Universitat de València, 2004. Survey of Social and Health Care Needs in the Valencian Autonomous Region, 2001.

The results show high percentages of well-placed users in all facilities for the elderly, with a global figure of $70 \%$, except for the Home Help Service where almost half of the users have profiles which are more similar to those using other facilities. Some users (20.3\%) who are dependent and lack social support should be cared for in Nursing Homes, whereas others $(18.8 \%)$ have a high degree of independence for ADL and could be covered by Phone Assistance. The Home Help Service in Spain is often used by people who are practically independent but who have a low income so they request assistance for domestic help only.

In the case of Nursing Homes, there is also a group of people who are classified in theory under Home Help Service (14\%) because they are independent for basic activities of daily living (BADL) and have some social or family support.

In the Day Centres, too, there are people with a very low level of social support who should be in Nursing Homes (11.1\%) and others who could receive Home Help Service (14.8\%) which would provide sufficient personal and home assistance to relieve the family carer.

Some patients who receive care in their homes from the Units for Home Hospitalisation could be treated in Hospitals for Chronically Ill and Long-stay Patients. But it is precisely the possibility of a higher quality of life in their homes and the vacating of hospital beds that is the raison d'être this service. The profiles of many of the users of both resources are very similar.

Finally, Table 4 shows that the great majority of users of the Hospital for Chronically Ill and Long-stay
Patients are well-placed (83\%). This tallies with the findings in the previous analysis of ideal user profiles.

Although the different weighting of the variables included in this analysis leads to different classifications, this approach allows us to examine the different care alternatives.

\section{Discussion}

The population on which we focused is the community of dependent persons, that is, persons having reduced autonomy for the activities of daily life.

The suitability of facilities to users' needs was studied using an external criterion based on the institutional profile of users of each facility in terms of the variables that could be observed in each person.

The results of objective analysis show that the suitability index for the different resources is high, between 0.661 among outpatients facilities such as Units for Home Hospitalisation and 1.000 among hospital facilities such as Units for psychiatric hospitalisation. Hence, very few users are badly placed in facilities, showing that the diagnostic evaluation carried out by social workers or medical services is correct, and that the basic needs of users of facilities are largely being met.

However, the fact that the diagnosis is correct and the care provided is sufficient does not mean that the facility assigned is the most suitable, as there are other variables which are not covered by this study, such as the time users remain in the facilities (especially in 
hospitals). Therefore, even if a patient is well-placed in a hospital, this does not necessarily mean that the stay could not be shortened, without reducing the quality of care, by using other home and/or community health and social resources.

Discriminant analysis shows that a substantial percentage of patients treated in hospitals-a very expensive resource offering a low quality of life-have a profile identical to other patients receiving care through outpatients and at-home resources. Our analysis shows that over one-third $(21.9 \%)$ of the cases dealt with by Units for Psychiatric Hospitalisation could perhaps be treated in Units for Mental Health, which is a more economical outpatients facility that also allows patients to remain within their social and family environment. Among frail patients aged over 60 (with multiple chronic, degenerative and/or acute illnesses), $17 \%$ of patients admitted to Hospitals for Chronically Ill and Long-stay Patients present profiles similar to patients cared for in Nursing Homes (temporary stays), Units for Home Hospitalisation and the Home Help Service, implying that they could perhaps be cared for through these facilities.

If we compare the data for suitability in each facility obtained from the two procedures used, there are several similarities which indicate coherence in the study. Also, the suitability index obtained in Hospitals for Chronically Ill and Long-stay Patients (0.822) is practically identical to the result of discriminant analysis $(83 \%)$. This is also the case in Units for Mental Health (suitability index 0.92, discriminant analysis $91.5 \%$ ).

The growing demand for social and health care in the Mediterranean welfare states is such a threat to their financial sustainability that it is essential to optimise the use of facilities. The fundamental requisite is knowledge of the needs of the people demanding such facilities. The first step is to offer efficient services, providing a perfect fit with demand. It is, therefore necessary to take specific measures, such as the following:

- Review the enforcement of Spanish regulations for certain social facilities, such as Nursing Homes.

- Extend and improve accessibility to the limited network of resources, and introduce technological improvements in existing services such as the Home Help Service or Phone Assistance. This would receive the burden of care currently borne by families.
- Improve the protocols for overall evaluation and referral of patients to health and social facilities (low suitability percentages in some cases), especially in order to establish a continuum of care through a single network of social and health facilities for dependent persons.

This paper tries to suggest procedures for studying care needs and shows one path of interest, namely, that optimisation of resources is possible while raising patients' quality of life in a sustainable fashion.

\section{Acknowledgements}

The studies presented in this paper received finance from the Ministry for Science and Technology, through the Spanish National R+D+I Plan (2000-2003); and from the Generalitat Valenciana, Conselleria de Sanidad, 2001, 2002 y 2003.

\section{References}

[1] Saltman R, Figueras J, editors. European health care reform: analysis of current strategies. Copenhagen: WHO - Regional Office for Europe; 1997.

[2] Dixon A, Mossialos E, editors. Health care systems in eight countries: Trends and challenges. 1st ed. London: The London School of Economics \& Political Science; 2002.

[3] Mossialos E, Dixon A, Figueras J, Kutzin J, editors. Funding health care: options for europe. 1st ed. Buckingham, Philadelphia: Open University Press; 2002.

[4] EUSTAT. La situación social en la Unión Europea. 2004 perspectivas. Belgium: European Commission; 2004.

[5] European Commission. Feasibility study. Comparable statistics in the area of care of dependent adults in the European Union. Luxembourg: Office for Official Publications of the European Communities; 2003.

[6] Directorate-General for Economic and Financial Affairs. Incorporating the sustainability of public finances into the Stability and Growth Pact. European Economy 2002;3:62-74.

[7] Directorate-General for Economic and Financial Affairs. The long-term sustainability of public finances. European Economy 2002;3:32-6.

[8] Docteur E. Measuring the quality of care in different settings. Health Care Finance Review 2001;22(3):59-70.

[9] Purandare N, Burns A, Challis D, Morris J. Perceived mental health needs and adequacy of service provision to older people in care homes in the UK: a national survey. International Journal of Geriatric Psychiatry 2004;19(6):549-53.

[10] Renau J, Pérez I, Gosalez E, Alós M. Utilización inapropiada de la hospitalización: el AEP. Mapfre Medicina 1998;9:197-206. 
[11] Ruipérez I, Midón J, Gómez-Pavón J, Maturana N, Gil P, Sancho M, Macias JF. Informe 2003: Nivel de adecuación de los recursos geriátricos en los hospitales generales españoles. Revista Española Geriatrie Gerontol 2003;38(4):281-7.

[12] Owen J, Cooke J, Wilson A. Research and development at the health and social care interface in primary care. A scoping exercise in one National Health Service Region. Health \& Social Care Community 2002;10(6):435-44.

[13] Garcés J, Ródenas F, Sanjosé V. Care needs among the dependent population in Spain: an empirical approach. Health \& Social Care Community 2004;12(6):466-74.

[14] Garcés J, Ródenas F, Sanjosé V. Towards a new welfare state: the social sustainability principle and health care strategies. Health Policy 2003;65:201-15.

[15] George V, Stathopoulos P, Garcés J. Squaring the welfare circle and government ideology: Greece and Spain in the 1990s. International society of security review 1999;52(4):4767.

[16] Martínez M, Delgado MD, Porta B, Zafra E, Izquierdo M, Carrasco E. Guía de recursos sociosanitarios de la Comunidad Valenciana. Valencia: Generalitat Valenciana; 2000
[17] Garcés J. La nueva sostenibilidad social. 1st ed. Barcelona: Ariel; 2000.

[18] Brown L, Tucker C, Domokos T. Evaluating the impact of integrated health and social care teams on older people living in the Community. Health \& Social Care Community 2003;11(2):85-94.

[19] Kane RL, Chen Q, Finch M, Blewett L, Burns R, Moskowitz M. The optimal outcomes of post-hospital care under Medicare. Health Services Research 2000;35(3):615-61.

[20] Mahoney FI, Barthel DW. Functional evaluation: the Barthel index. Maryland State Medical Journal 1965;14:61-5.

[21] Bond MJ, Harris RD, Smith DS, Clark MS. An examination of the factor structure of the frenchay activities index. Disability and Rehabilitation 1992;14(1):27-9.

[22] Folstein MF, Folstein SE, McHugh PR. Mini-Mental State. A practical method for grading the cognitive state of patients for the clinician. Journal of Psychiatric Research 1975;12(3):189-98.

[23] Lobo A, Gómez Burgada F, Sala JM, Seva Díaz A. El MiniExamen Cognoscitivo en pacientes geriátricos. Folia Neuropsiquiátr 1979;14:244-51. 